\title{
Incremento de área em sementes de moringa durante a embebição por meio da análise de imagens
}

\author{
Area increment in moringa seeds during imbibition by image analysis \\ Bruno Gomes de Noronha', André Dantas de Medeiros ${ }^{\mathrm{II}}$, Márcio Dias Pereira ${ }^{\mathrm{III}}$
}

\begin{abstract}
Resumo
A morfologia das sementes e as modificações físicas sofridas por elas durante a germinação podem estar associadas ao vigor. Por isso, objetivou-se com este trabalho monitorar o incremento de área em sementes de moringa durante a embebição, por meio da análise de imagens, com o intuito de se determinar a sua qualidade fisiológica a partir deste incremento. Utilizaram-se sementes de quatro lotes de moringa com e sem tegumento, fotografadas antes e durante a embebição, nos períodos de 8,16 e 24 horas, nas temperaturas de 15 e $20^{\circ} \mathrm{C}$. Calculou-se o incremento de área (\%) através da análise das imagens, utilizando-se o programa ImageJ. Os resultados de cada período avaliado foram comparados com os testes usualmente utilizados na avaliação do vigor de sementes. O delineamento foi inteiramente casualizado, com quatro repetições de 50 sementes por tratamento. Os dados foram submetidos a ANOVA e comparados pelo teste de Tukey. Os lotes 1, 2 e 4 foram considerados de melhor qualidade, enquanto o lote 3 apresentou qualidade inferior, quando comparado aos demais lotes testados. As sementes de moringa seguiram o padrão trifásico de embebição, com a protrusão da raiz primária ocorrendo em 72 horas. Foi possível avaliar o percentual de incremento de área por meio do programa ImageJ, sendo o período de 8 horas de embebição a $15^{\circ} \mathrm{C} \mathrm{o}$ que demonstrou maior eficiência para classificação dos lotes quanto a sua qualidade fisiológica.
\end{abstract}

Palavras-chave: Qualidade; Vigor; Espécie florestal

\begin{abstract}
The seed morphology and the physical modifications undergone by them during germination may be associated with vigor. Therefore, the aim of this work was to monitor the increase of area in Moringa seeds during imbibition, by means of image analysis, in order to determine their physiological quality. Seeds of four Moringa lots with and without tegument, photographed before and during soaking, were used in the periods of 8,16 and 24 hours, at temperatures of 15 and $20^{\circ} \mathrm{C}$. The area increase (\%) was calculated by image analysis using the ImageJ program. The results of each evaluated period were compared with the traditional tests of germination and vigor. The design was entirely randomized, with four replicates of 50 seeds per treatment. Data were submitted to ANOVA and compared by the Tukey test. Lots 1, 2 and 4 were considered better quality, while lot 3 presented lower quality when compared to the other lots tested. Moringa seeds followed the three-phase pattern of imbibition, with protrusion of the radicle occurring in 72 hours. It was possible to evaluate the percentage of increment of area through the program ImageJ, being the period of 8 hours of imbibition at $15^{\circ} \mathrm{C}$ which demonstrated greater efficiency to classify the lots as to their quality.
\end{abstract}

Keywords: Quality; Vigor; Forest species

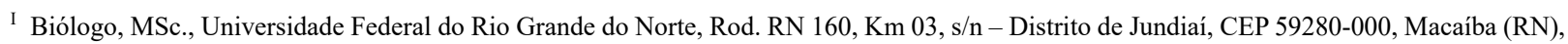
Brasil. asphael@gmail.com (ORCID: 0000-0002-3245-5312)

II Engenheiro Agrônomo, Mestrando do Programa de Pós-Graduação em Fitotecnia, Universidade Federal de Viçosa, Av. PH Rolfs, s/n, Campus Universitário, CEP 36570900, Viçosa (MG), Brasil. medeiros.seeds@gmail.com (ORCID: 0000-0002-1097-0292)

III Engenheiro Agrônomo, Dr., Professor Adjunto do Departamento de Agropecuária, Universidade Federal do Rio Grande do Norte, Rod. RN 160, Km 03, s/n, Distrito de Jundiaí, CEP 59280-000, Macaíba (RN), Brasil. marcioagron@yahoo.com.br (ORCID: 0000-0001-9729-6503)
} 


\section{Introdução}

A análise computadorizada de imagens tem se destacado como técnica em potencial para a avaliação da qualidade de sementes, de modo especial em avaliações do vigor, detectando lotes que possam apresentar melhor desempenho no campo (XU; FUJIMURA; MCDONALD, 2007).

Os resultados obtidos através do uso da análise de imagens destacam-se principalmente pelas informações obtidas, relacionadas à morfologia das sementes, que podem ser associadas ao seu potencial fisiológico (ZABOT et al., 2008). Em geral, as imagens captadas são processadas com o auxílio de programas como o Tomato Analyzer ${ }^{\circledR}$ (MARCOS FILHO; KIKUTI; LIMA, 2009; WENDT, 2014), ImagePro Plus $^{\circledR}$ (SILVA; CICERO; BENNETT, 2012), SVIS ${ }^{\circledR}$ (ALVARENGA; MARCOS-FILHO; GOMES JUNIOR, 2012) e Image $J^{\circledR}$ (SILVA et al., 2013), que permitem determinar segmentos das sementes e estabelecer relações entre suas estruturas internas ou externas e a sua qualidade fisiológica.

Uma das vertentes utilizadas nesses testes com análise de imagens digitais consiste na captura da imagem para geração de dados dimensionais, como o comprimento e a área (DELL'ÁQUILA, 2009; VARMA; DURGA; KESHAVULU, 2013), determinando-se a sua mensuração através de métodos de contagem ou frequência. A avaliação da viabilidade de sementes por meio da análise de imagens constituise em um método objetivo, econômico, rápido e prático. Estas análises levam em consideração, para fins de comparação, os valores de germinação e o vigor das sementes, cujas imagens foram analisadas, traçando uma relação entre o que se observou nas imagens e o seu desempenho.

Para que a germinação ocorra, há um teor mínimo de água que a semente deve absorver e este varia com a espécie (BEWLEY et al., 2013). A semente aumenta de volume durante o avanço das fases do processo de embebição, durante a germinação (FERREIRA; BORGHEETTI, 2008). Existem casos em que ocorrem diferenças acentuadas no aumento do tamanho das sementes que podem estar correlacionadas com a viabilidade (TAIZ; ZEIGER, 2013).

A relação entre a qualidade das sementes, aumento de peso ou de tamanho durante a hidratação foram observados em sementes de soja (BECKERT; MIGUEL; MARCOS FILHO, 2000; KOIZUMI et al., 2008), constatando-se que as sementes que apresentaram menor aumento de volume durante as fases de embebição, demonstraram qualidade inferior.

Como a embebição, em geral, reflete no aumento da semente, a avaliação desse aumento por meio de imagens que destaquem mudanças durante as fases, principalmente iniciais de absorção de água, pode permitir o ranqueamento de lotes em níveis de vigor, sendo um processo de análise relativamente rápido e preciso (GOMES JUNIOR; CHAMMA; CICERO, 2014). Entretanto, não há muitos relatos de pesquisas envolvendo a análise de imagens de sementes durante a embebição e sua relação com a qualidade fisiológica.

A análise de imagens de sementes representa uma alternativa complementar, reproduzível e rápida (DELL'ÁQUILA, 2009; MARCOS-FILHO; KIKUTI; LIMA, 2009; SILVA et al., 2013), características importantes que permitem agilidade na tomada de decisões (GOMES JUNIOR; CHAMMA; CICERO, 2014), não só na análise de sementes de espécies cultivadas, mas também das florestais como a Moringa oleifera Lam. (moringa).

A moringa é espécie mais conhecida da pequena família Moringaceae que apresenta num total de 14 espécies, sendo originário do norte Indiano, e bastante distribuída em países tropicais (RAMOS et al., 2010). É uma planta rústica, de rápido crescimento e com folhas, flores e frutos comestíveis. Essas qualidades fazem com que a moringa seja uma planta bastante adequada para o cultivo nas regiões áridas do Brasil (SOUZA; LORENZI, 2008), Além disso, esta espécie apresenta sementes oleaginosas (LORENZI; MATOS, 2002), o que lhe confere grande potencial para a extração de óleo destinado à produção de biocombustível (RASHID; ANWAR; KNOTHE, 2008), além de apresentar adaptações às regiões semiáridas, caracterizadas principalmente pelos baixos índices de pluviosidade (BEZERRA; MOMENTÉ; MEDEIROS FILHO, 2004).

$\mathrm{O}$ objetivo deste trabalho foi monitorar o incremento de área em sementes de moringa durante a embebição, por meio da análise de imagem, para determinar a qualidade fisiológica. 


\section{Material e métodos}

O experimento foi realizado no laboratório de análise e pesquisa de sementes da Universidade Federal do Rio Grande do Norte.

Utilizaram-se quatro lotes de sementes de moringa coletadas na maturidade fisiológica em árvores-matrizes localizadas na região de Macaíba - RN, que possui altitude média de $11 \mathrm{~m}$, clima tropical (Aw), pluviosidade de $1135 \mathrm{~mm} /$ ano e temperatura média anual de $28,5^{\circ} \mathrm{C}$. A região se localiza entre as coordenadas $05^{\circ} 51^{\prime} 30^{\prime \prime} \mathrm{S}$ (latitude) e $35^{\circ} 21^{\prime} 14^{\prime \prime} \mathrm{W}$ (Longitude). Os lotes foram compostos a partir de sementes recolhidas de árvores-matrizes localizadas a menos de 50 metros uma da outra, utilizando-se nove matrizes, distantes seis metros uma da outra e com aspecto saudável. Após a colheita, as sementes foram levadas para o laboratório, no qual foram retiradas dos frutos e imediatamente submetidas aos testes e avaliações.

Para fins de caracterização do processo de embebição das sementes de moringa, procedeu-se a determinação da curva de embebição. Para tanto, utilizaram-se 4 repetições de $10 \mathrm{~g}$ de sementes com e sem tegumento, distribuídas em papel germitest embebido com água destilada, na proporção de 2,5 vezes o peso do papel, para os quatro lotes. As sementes foram mantidas em B.O.D. a 15 e $20^{\circ} \mathrm{C}$, na ausência de luz. As avaliações para obtenção da curva de embebição foram realizadas a cada duas horas nas primeiras 24 horas, e após este tempo, ocorreram a cada 12 horas, até a protrusão radicular de pelo menos $50 \%$ das sementes. Para avaliar o ganho de água pelas sementes, foram realizadas pesagens, em balança analítica das sementes secas e após, 2, 4, 6, 8, 10, 12, 24, 48, 72 e 96 horas de embebição.

Para determinar a qualidade das sementes, realizou-se a caracterização fisiológica das mesmas, utilizando-se os seguintes testes: Germinação - considerou-se o número de plântulas normais, ou seja, aquelas que apresentam comprimento total (epicótilo + raiz primária) de pelo menos quatro vezes o tamanho da semente e sem anomalias, como descrito por Brasil (2009), neste caso foram consideradas as plântulas que tinham comprimento igual ou maior que $6 \mathrm{~cm}$; primeira contagem de germinação - foi conduzido conjuntamente com o teste de germinação e seguindo as recomendações de Bezerra, Momenté e Medeiros Filho (2004); velocidade de germinação - também foi realizado junto com o teste de germinação, avaliando-se o número de sementes germinadas diariamente e calculado o índice de velocidade de germinação (IVG), de acordo com a fórmula descrita por Maguire (1962); comprimento de plântulas - as plântulas foram medidas individualmente com o auxílio de uma régua graduada, de acordo com a metodologia definida por Krzyzanowski, Vieira e França Neto (1999); massa seca de plântulas determinada em estufa, como recomendado por Nakagawa (1999).

Para o monitoramento do incremento de área, por meio da análise de imagem, foram utilizadas sementes dos quatro lotes de moringa, previamente desinfestadas com hipoclorito de sódio a $2 \%$ por dois minutos e lavadas três vezes seguidas com água destilada, retirando-se o excesso de umidade com papeltoalha. Foram utilizadas sementes com e sem tegumento, sendo a destegumentação realizada manualmente com o auxilio de um estilete. Em seguida, as sementes foram dispostas em papel-germitest com o hilo voltado para baixo, numeradas e suas posições foram marcadas, em fileiras de 10 sementes, perfazendo um total de cinco fileiras por rolo, sendo fotografadas logo em seguida, utilizando equipamento fotográfico Samsung N700, a uma distância de $30 \mathrm{~cm}$ das sementes. Utilizou-se um tripé para que a todas as imagens fossem obtidas com a mesma distância, utilizando uma régua graduada em milímetros como escala, e mantida a mesma condição para todas as sementes. Em seguida, procedeu-se o umedecimento do papel e a confecção de rolos, que foram mantidos em incubador tipo B.O.D. a 15 e $20^{\circ} \mathrm{C}$. Esse processo foi repetido para as imagens das sementes antes do início e após a embebição $(0,8,16$ e 24 horas).

Para o cálculo do incremento de área foi utilizada a seguinte fórmula:

$$
\text { I. } A=\frac{(A f-A i) * 100}{A i}
$$

Em que: I.A = Percentual de incremento de área na semente durante o período de embebição; Ai = Área inicial da semente antes do início da embebição; Af = Área final após a embebição.

Ci. Fl., Santa Maria, v. 29, n. 1, p. 221-232, jan./mar., 2019 
As médias das repetições foram submetidas à análise de variância, sendo a comparação de médias dos lotes, para cada variável avaliada, efetuada pelo teste de Tukey, a 5\% de probabilidade, utilizando o programa SAS ${ }^{\circledR}$. Realizou-se também o teste de coeficiente de correlação simples de Pearson $(p)$ entre a área de sementes embebidas e o comprimento de plântulas.

\section{Resultados e discussão}

Na Figura 1 apresentam-se os resultados das curvas do peso de massa úmida (g) e da quantidade de água (g) das sementes, nas quais observa-se que a absorção de água pelas sementes de moringa segue o padrão trifásico de embebição. No total foram necessárias 72 horas de hidratação para que ocorresse a protrusão da raiz primária.

Figura 1 - Curva de embebição de sementes de quatro lotes de Moringa oleifera com tegumento, mantidas a $15^{\circ} \mathrm{C}(\mathrm{A})$ e $20^{\circ} \mathrm{C}(\mathrm{B})$ e sem tegumento a $15^{\circ} \mathrm{C}(\mathrm{C})$ e $20^{\circ} \mathrm{C}(\mathrm{D})$, baseada no acréscimo de massa úmida (g) ao longo do tempo (h).

Figure 1 - Seed imbibition curve of four plots of Moringa oleifera with tegument, maintained $15^{\circ} \mathrm{C}(\mathrm{A})$ and $20^{\circ} \mathrm{C}$, (B) and without tegument at $15^{\circ} \mathrm{C}(\mathrm{C})$ and $20^{\circ} \mathrm{C}(\mathrm{D})$, based on the gain of wet mass (g) over time (h).
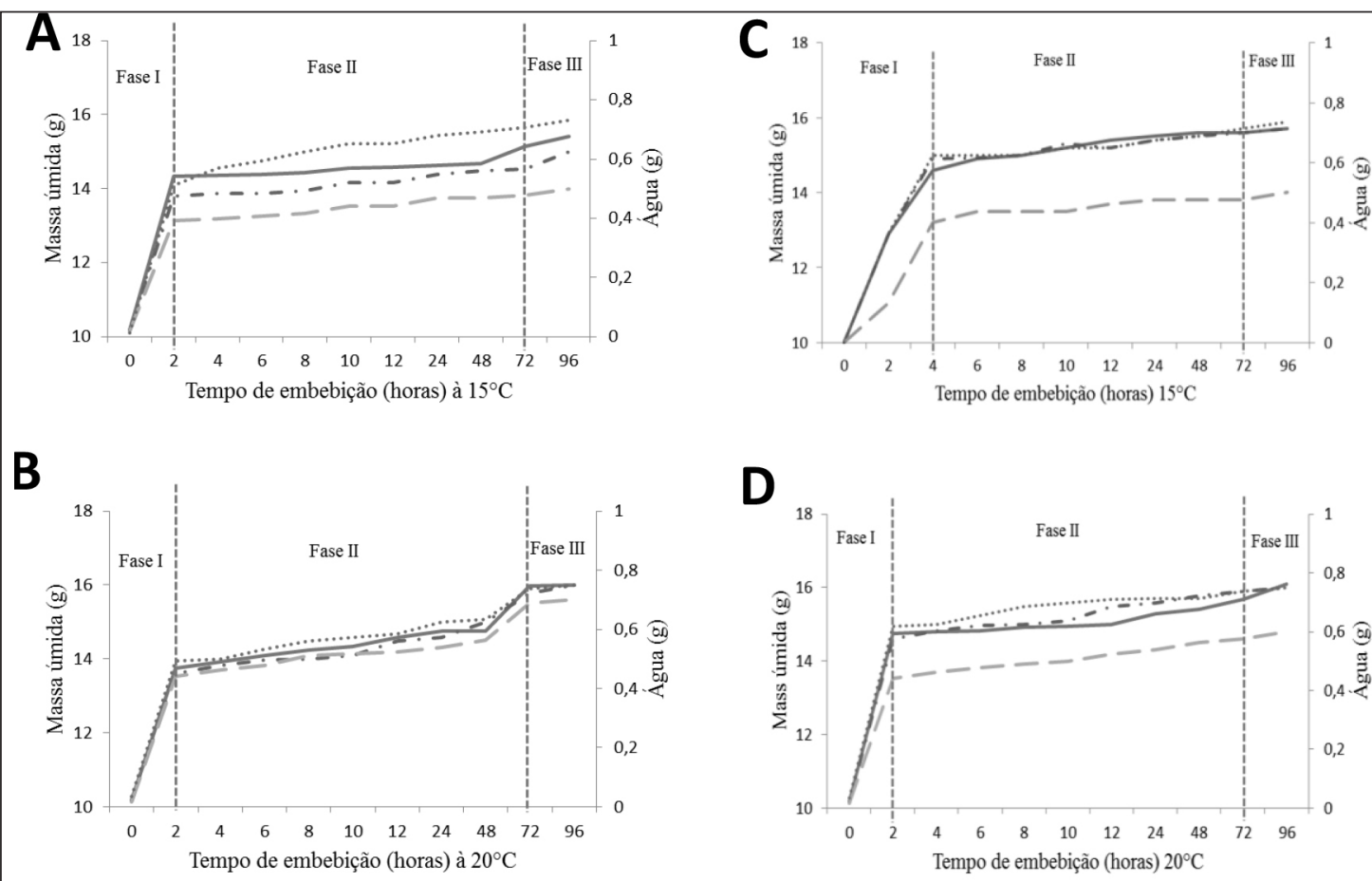

Lote 1

Lote 2 - -

Lote 3

Lote 4 ...........

A absorção de água na primeira fase foi relativamente rápida em todos os tratamentos, seguida por uma fase de estabilização ocorrendo depois a retomada na absorção de água. Esta última fase observada só ocorre quando a germinação é completa, sendo que, nesta etapa, o eixo embrionário se alonga e rompe as estruturas de cobertura da semente, caracterizado pela emissão da raiz primária (RABANNI et al., 2013).

A Fase I foi observada nas primeiras horas de embebição, com alta velocidade de absorção de água e ganho de massa. Observou-se que os lotes testados apresentaram variações quanto à absorção de água, em função das temperaturas e da presença e ausência do tegumento, sendo que a taxa de absorção de água na fase I a $15^{\circ} \mathrm{C}$ com sementes sem o tegumento (Figura 1C), apresentou aumento do tempo, cerca de 4 horas, para atingir o início da fase II, enquanto nos demais, essa mesma fase ocorreu em 2 horas. Carvalho 
e Nakagawa (2000) afirmaram, para sementes em geral, que essa fase possui duração de uma a duas horas, corroborando os dados apresentados.

Baixas temperaturas diminuem a taxa de absorção, isso ocorre em razão da temperatura influenciar em alguns aspectos fisiológicos, dentre eles a conformação das membranas, alterando o processo de absorção (SILVA; NASCIMENTO, 2010). Em suas pesquisas Coll et al. (2001) explicam que a velocidade de absorção e a quantidade de água embebida variam com a natureza e composição do tegumento. A moringa apresenta um tegumento poroso e liso, que facilita a absorção de água (BEZERRA; MOMENTÉ; MEDEIROS FILHO, 2004), além disso, a alta concentração de proteínas favorece o condicionamento osmótico (GALLÃO; DAMASCENO; BRITO, 2006).

Os resultados obtidos neste trabalho diferiram daqueles encontrados por Alves et al. (2005) ao estudarem o efeito dos fatores de embebição e presença do tegumento em sementes de moringa, que verificaram que as sementes sem o tegumento não sofriam mudanças no padrão de embebição. No presente trabalho, as sementes que estavam com tegumento e sem tegumento apresentaram diferenças entre si, sendo que as sementes sem o tegumento (Figura $1 \mathrm{C}$ e D) absorveram mais água do que aquelas com o tegumento (Figura $1 \mathrm{~A}$ e B) durante a Fase I.

Para a germinação (Tabela 1) observa-se que os lotes 1, 2 e 4, apresentaram 86,89 e $88 \%$ de plântulas normais, respectivamente, não sendo identificadas diferenças significativas entre eles, no entanto, o lote 3 apresentou apenas $48 \%$ de plântulas normais.

Tabela 1 - Plântulas normais (PN), primeira contagem (PC), índice de velocidade de germinação (IVG), plântulas anormais (PA), sementes mortas (M), média do comprimento parte aérea $(\mathrm{A}) \mathrm{e}$ radicular (R), média da massa seca (MS) de plântulas de quatro lotes de Moringa oleífera.

Table 1 - Normal seedlings (PN), first count (PC), germination speed index (IVG), abnormal seedlings (AP), dead seeds $(\mathrm{M})$, mean aerial length $(\mathrm{A})$ and radicular $(\mathrm{R})$ mean dry mass $(\mathrm{DM})$ of four seedlings of Moringa oleifera.

\begin{tabular}{|c|c|c|c|c|c|c|c|c|}
\hline Lote & $\begin{array}{l}\text { PN } \\
\text { (\%) }\end{array}$ & $\begin{array}{l}\text { PC } \\
(\%)\end{array}$ & IVG & $\begin{array}{l}\text { PA } \\
(\%)\end{array}$ & $\begin{array}{c}M \\
(\%)\end{array}$ & $\begin{array}{c}\mathrm{A} \\
(\mathrm{cm})\end{array}$ & $\begin{array}{c}\mathrm{R} \\
(\mathrm{cm})\end{array}$ & $\begin{array}{r}\text { MS } \\
\text { (g) }\end{array}$ \\
\hline 1 & $86 \mathrm{a}$ & $80 \mathrm{a}$ & $3,90 \mathrm{~b}$ & $4,0 \mathrm{~b}$ & $10,5 \mathrm{~b}$ & $5,89 \mathrm{~b}$ & $8,89 \mathrm{a}$ & $0,284 b$ \\
\hline 2 & $89 a$ & $75 \mathrm{~b}$ & $5,74 \mathrm{a}$ & $1,0 \mathrm{a}$ & $10,0 \mathrm{~b}$ & $5,86 \mathrm{~b}$ & $8,14 \mathrm{a}$ & $0,289 \mathrm{~b}$ \\
\hline 3 & $48 \mathrm{~b}$ & $30 \mathrm{c}$ & $3,62 \mathrm{~b}$ & $7,0 \mathrm{c}$ & $45,5 \mathrm{a}$ & $3,48 \mathrm{c}$ & $3,08 \mathrm{c}$ & $0,176 \mathrm{c}$ \\
\hline 4 & $88 \mathrm{a}$ & $76 \mathrm{~b}$ & $7,05 \mathrm{a}$ & $1,0 \mathrm{a}$ & $11,5 \mathrm{~b}$ & $6,41 \mathrm{a}$ & $6,95 \mathrm{~b}$ & $0,313 \mathrm{a}$ \\
\hline $\mathrm{F}$ & $6,216^{* *}$ & $6,435^{* *}$ & $13,76^{* *}$ & $7,863^{* *}$ & $7,892 * *$ & $6,537^{* *}$ & $7,291 * *$ & $6,417 * *$ \\
\hline d.m.s & 2,0 & 2,10 & 1,83 & 0,3 & 1,5 & 0,28 & 0,73 & 0,058 \\
\hline CV (\%) & 1,64 & 1,56 & 17,18 & 6,3 & 3,55 & 2,47 & 1,63 & 1,04 \\
\hline
\end{tabular}

**/* Significativo a 1 e $5 \%$ de probabilidade pelo teste F. Médias seguidas de mesma letra na coluna não diferem estatisticamente entre si pelo teste de Tukey a $5 \%$ de probabilidade.

Para a primeira contagem de germinação (Tabela 1), observou-se ranqueamento dos lotes diferentes daquela encontrada no teste de germinação, sendo o lote 1 o que apresentou maior germinação ( $80 \%)$, os lotes 2 e 4 apresentaram qualidade intermediária ( 75 e 76\%, respectivamente) e o lote 3 apresentou desempenho inferior, sendo observado que apenas 30\% das sementes germinaram aos 5 dias após a semeadura. O resultado obtido para a variável índice de velocidade de germinação (Tabela 1) indicou que os lotes 2 e 4, apresentaram valores próximos (5,74 e 7,05, respectivamente), enquanto para os lotes 1 e 3 , observou-se resultado inferior (3,90 e 3,62, respectivamente). Estes dados corroboram os trabalhos de outros autores envolvendo germinação e IVG de sementes de moringa, sendo observados valores muito próximos, tanto para testes com diversas temperaturas, peso da semente e substratos em que a média observada variou de 38 a 97\% de germinação e de 1,1 a 5,7 para o IVG (BEZERRA; MOMENTÉ; MEDEIROS FILHO, 2004; TARGINO et al., 2015). 
Um dos conceitos mais antigos de vigor de sementes está relacionado à velocidade de germinação, frequentemente registram-se diferenças na velocidade de germinação, sugerindo que existem diferenças de vigor entre eles (NAKAGAWA, 1999), sendo mais vigorosas, portanto, aquelas sementes com maior velocidade de germinação. Assim, o teste de primeira contagem de germinação tem como objetivo determinar o vigor relativo do lote de sementes, avaliando a porcentagem de plântulas normais presentes na primeira contagem de germinação (KRZYZANOWSKI; VIEIRA; FRANÇA NETO, 1999). Os resultados obtidos por diferentes autores, com sementes de Amburana cearenses (GUEDES et al., 2013), Cedrela fissilis (LAZAROTTO et al., 2013) e Moringa oleifera (BEZERRA; MOMENTÉ; MEDEIROS FILHO, 2004), também indicam que a velocidade de germinação, por meio da primeira contagem de germinação, pode se diferenciar viabilidade, por exprimir aspectos do vigor das sementes e o seu potencial para formar plantas mais resistentes e vigorosas. Além disso, essas diferenças estão relacionadas com as condições edafoclimáticas em que as sementes foram produzidas

Na Tabela 1 observa-se que os resultados para o número de plântulas anormais em cada lote não seguiram a mesma tendência observada nos testes de germinação, primeira contagem e IVG, sendo os lotes 2 e 4 os que apresentaram menor quantidade de plântulas com deformações (1\%) e o lote 1 que foi classificado como lote de qualidade intermediária, com $4 \%$ de plântulas anormais, o lote 3 apresentou o menor desempenho, $7 \%$ de plântulas com algum tipo de malformação que as considerassem anormais.

Segundo Brasil (2009), plântulas anormais são aquelas que não mostram potencial para continuar seu desenvolvimento e dar origem a plantas normais mesmo em condições favoráveis, podendo estar ligado a características genéticas ou físicas durante o preenchimento do grão. Em pesquisas com Ricinus communis, Goneli et al. (2011) observaram que a redução do valor de massa seca diminui a qualidade das sementes e aumenta a quantidade de plântulas anormais geradas, sendo que, quanto menor a massa seca acumulada pelas sementes, pior a qualidade do lote.

$\mathrm{Na}$ análise de sementes mortas, que de acordo com Brasil (2009) são as sementes que no final do teste não germinam, não estão duras, nem dormentes, e geralmente, apresentam-se amolecidas, atacadas por microrganismos e não apresentam nenhum sinal de início de germinação; os lotes 1, 2 e 4 apresentaram médias 11,10 e $12 \%$, respectivamente, não diferindo entre si. Já o lote 3 , que foi detectado nos testes anteriormente citados como o de qualidade inferior, também apresentou o maior percentual de sementes mortas que foi de $46 \%$.

$\mathrm{Na}$ avaliação do comprimento de partes das plântulas (parte aérea e raiz primária) de moringa, foi possível detectar que as sementes do lote 3 produziram parte aérea e raiz primária menores, quando comparado com os demais lotes, sendo 3,48 e $3,08 \mathrm{~cm}$, respectivamente. No entanto, para o comprimento de parte aérea, o lote 4 apresentou maior resultado $(6,41 \mathrm{~cm})$ e os lotes 1 e 2, valores intermediários que não diferiram entre si $(5,89$ e 5,86 cm). Para o comprimento da raiz primária, os lotes 1 e 2 foram os que apresentaram maior crescimento $(8,89$ e $8,14 \mathrm{~cm})$ e o lote 4 , crescimento intermediário $(6,95 \mathrm{~cm})$ (Tabela 1).

Em relação à massa seca, também se observou que o lote 3 foi o que apresentou menor massa $(0,176$ g), os lotes 1 e 2 não diferiram entre si na comparação de massa seca $(2,84$ e 2,89 g), respectivamente, enquanto o lote 4 obteve maior acúmulo de massa seca $(0,313 \mathrm{~g})$ sendo visualmente o lote que também apresentou as maiores sementes. De acordo com Bewley et al. (2013), as substâncias de reserva são acumuladas para fornecimento de energia e substâncias básicas para o desenvolvimento do processo de germinação, deste modo, menor acúmulo de massa seca resultaria em menor vigor das sementes e menor desenvolvimento de plântulas, quando comparadas com aquelas de lotes em que se observa maior acúmulo de reservas.

De modo geral, a caracterização fisiológica das sementes por meio dos testes de viabilidade e vigor detectou que o lote 4 foi o que apresentou maior vigor, os lotes 1 e 2 como sendo de qualidade intermediária e, por fim, o lote 3 como o de menor qualidade fisiológica.

$\mathrm{Na}$ análise dos resultados obtidos a partir do teste de incremento de área (Tabela 2), para semente com o tegumento, foi possível observar que em 8 horas de embebição a $15^{\circ} \mathrm{C}$, o lote 4 foi o que apresentou maior percentual de incremento $(14,7 \%)$, sendo que, para os lotes 1 e 2 não houve diferença significativa (12,6 e 13,0\%, respectivamente), enquanto o lote 3 apresentou o menor percentual $(11,3 \%)$. Esse ranqueamento não se repetiu após 16 horas de embebição (Tabela 2), uma vez que os lotes 1, 2 e 4 apresentaram maiores porcentagens $(22,2,22,1$ e 22,5\%) de incremento de área, não diferindo entre si, enquanto o lote 
3 apresentou o menor percentual de incremento de área (18,5\%). Apesar de ter sido possível separar os lotes de menor qualidade nesse período de embebição, este foi o que apresentou menor sensibilidade para isto, equiparando os lotes 1,2 e 4, que apresentam diferenças de qualidade em outros testes, como descrito anteriormente.

Tabela 2 - Incremento de área (\%) em três períodos de embebição (8, 16 e 24 horas) nas temperaturas de 15 e $20^{\circ} \mathrm{C}$ em sementes com tegumento e sem tegumento, de quatro lotes de Moringa oleifera.

Table 2 - Area increase (\%) in three soaking periods (8, 16 and 24 hours) at temperatures of 15 and $20^{\circ} \mathrm{C}$ in seed with tegument and without tegument, from four lots of Moringa oleífera.

\begin{tabular}{|c|c|c|c|c|c|c|}
\hline \multirow{3}{*}{ Lotes } & \multicolumn{6}{|c|}{ Com Tegumento } \\
\hline & \multicolumn{3}{|c|}{$15^{\circ} \mathrm{C}$} & \multicolumn{3}{|c|}{$20^{\circ} \mathrm{C}$} \\
\hline & 8 & 16 & 24 & 8 & 16 & 24 \\
\hline 1 & $12,6 \mathrm{~b}$ & $22,2 \mathrm{a}$ & $24,9 \mathrm{~b}$ & $23,6 \mathrm{a}$ & $28,4 \mathrm{~b}$ & $39,7 \mathrm{~b}$ \\
\hline 2 & $13,0 \mathrm{~b}$ & $22,1 \mathrm{a}$ & $24,7 \mathrm{~b}$ & $22,1 \mathrm{~b}$ & $39,7 \mathrm{a}$ & $44,9 \mathrm{a}$ \\
\hline 3 & $11,3 \mathrm{c}$ & $18,5 \mathrm{~b}$ & $20,6 \mathrm{c}$ & $16,7 \mathrm{c}$ & $26,0 \mathrm{c}$ & $34,9 \mathrm{c}$ \\
\hline 4 & $14,7 \mathrm{a}$ & $22,5 \mathrm{a}$ & $33,4 \mathrm{a}$ & $16,2 \mathrm{c}$ & $29,6 \mathrm{~b}$ & $40,8 \mathrm{~b}$ \\
\hline $\mathrm{F}$ & $7,391 * *$ & $7,390 * *$ & $8,090 * *$ & $9,623 * *$ & $7,750 * *$ & $7,340 * *$ \\
\hline d.m.s & 1,6 & 0,9 & 3,1 & 0,8 & 0,3 & 3,1 \\
\hline \multirow[t]{2}{*}{$\mathrm{CV}(\%)$} & 5,43 & 2,13 & 6,0 & 1,16 & 0,6 & 3,31 \\
\hline & \multicolumn{6}{|c|}{ Sem Tegumento } \\
\hline \multirow{2}{*}{ Lotes } & \multicolumn{3}{|c|}{$15^{\circ} \mathrm{C}$} & \multicolumn{3}{|c|}{$20{ }^{\circ} \mathrm{C}$} \\
\hline & 8 & 16 & 24 & 8 & 16 & 24 \\
\hline 1 & $14,5 \mathrm{~b}$ & $23,8 \mathrm{~b}$ & $34,6 \mathrm{~b}$ & $20,2 \mathrm{~b}$ & $29,7 \mathrm{~b}$ & $39,7 \mathrm{~b}$ \\
\hline 2 & $14,4 \mathrm{~b}$ & $23,9 \mathrm{~b}$ & $34,8 \mathrm{~b}$ & $24,7 \mathrm{a}$ & $31,5 \mathrm{a}$ & $35,0 \mathrm{c}$ \\
\hline 3 & $11,0 \mathrm{c}$ & $20,1 \mathrm{c}$ & $30,7 \mathrm{c}$ & $19,8 \mathrm{bc}$ & $24,0 \mathrm{c}$ & $27,8 \mathrm{~d}$ \\
\hline 4 & $17,1 \mathrm{a}$ & $27,0 \mathrm{a}$ & $38,9 \mathrm{a}$ & $18,1 \mathrm{c}$ & $31,0 \mathrm{a}$ & $45,3 \mathrm{a}$ \\
\hline $\mathrm{F}$ & $7,684 * *$ & $7,281 * *$ & $7,832 * *$ & $5,503 *$ & $6,616^{*}$ & $7,507 * *$ \\
\hline d.m.s & 1,5 & 1,9 & 3,1 & 1,7 & 0,5 & 1,3 \\
\hline CV (\%) & 5,13 & 3,23 & 6,65 & 2,41 & 10,29 & 2,51 \\
\hline
\end{tabular}

**, * Significativo a 1 e $5 \%$ de probabilidade pelo teste F. Médias seguidas de mesma letra na coluna não diferem estatisticamente entre si pelo teste de Tukey a $5 \%$ de probabilidade.

Após 24 horas de embebição (Tabela 2), o ranqueamento dos lotes pelo incremento de área foi igual àquele obtido em 8 horas de embebição, sendo que, novamente o lote 4 apresentou maior percentual de incremento (33,4\%), os lotes 1 e 2 não diferiram entre si $(24,9$ e $24,7 \%)$ e o lote 3 apresentou o menor percentual de incremento de área $(20,6 \%)$ entre os quatro lotes testados.

$\mathrm{O}$ ranqueamento dos lotes com tegumento, segundo o incremento de área na temperatura de $20^{\circ} \mathrm{C}$ (Tabela 2) diferiu daquele descrito anteriormente à temperatura de $15^{\circ} \mathrm{C}$, uma vez que em 8 horas de embebição o lote 1 foi o que apresentou maior porcentagem de incremento de área $(23,6 \%)$. Para o lote 2 , esse valor foi menor $(22,1 \%)$, ao passo que para os lotes 3 e 4 não houve diferença significativa (16,7 e 16,2\%, respectivamente). Após 16 horas de embebição esse ranqueamento foi diferente, observando-se que os lotes 1 e 4 não apresentaram diferenças significativas (28,4 e 29,6\%, respectivamente), já o lote 2 foi o que apresentou maior percentual de incremento de área $(39,7 \%)$ e o lote 3 , o menor, $26,0 \%$.

O período de 24 horas de embebição apresentou ranqueamento igual ao período de 16 horas (Tabela 2) para sementes com tegumento, sendo novamente o lote 2 o que apresentou maior percentual 
$(44,9 \%)$, os lotes 1 e $4(39,7$ e 40,85\%) não apresentaram diferenças significativas e o lote 3 apresentou os menores resultados $(34,9 \%)$.

Para as sementes sem o tegumento e submetidas à temperatura de $15^{\circ} \mathrm{C}$, no período de 8 horas de embebição (Tabela 2), o lote 4 foi o que apresentou maior porcentagem de incremento de área $(17,1 \%)$, seguido dos lotes 1 e 2 sem diferenças significativas (14,5 e 14,4\%). O lote 3 apresentou menor percentual $(16,0 \%)$ de incremento de área, apresentando resultados semelhantes quando comparados com sementes que apresentavam tegumento.

Observou-se que o período de 16 horas de embebição (Tabela 2) para sementes sem o tegumento, permitiu ranqueamento igual àquele anteriormente descrito, sendo que o lote 4 evidenciou maior porcentagem de incremento de área (27,0\%), os lotes 1 e 2 em seguida (23,8 e 23,9\%, respectivamente) não apresentaram diferenças entre si, e o lote 3 apresentou a menor porcentagem $(20,1 \%)$ de aumento da área das sementes.

Para os períodos de embebição em que as sementes foram expostas à temperatura de $20^{\circ} \mathrm{C}$, sem o tegumento, o período de 8 horas de embebição (Tabela 2) evidencia que o lote 2 foi o que apresentou maior porcentagem de incremento (24,7\%), seguido do lote 1 , que apresentou valor intermediário $(20,2 \%)$, e em seguida o lote $3(19,8 \%)$, que não apresentou diferenças significativas entre os lotes 1 e 4.

No período de 16 horas de embebição observou-se que os lotes 2 e 4 apresentam os maiores valores de incremento de área (31,5 e 31,0\%), seguido do lote $1(29,7 \%)$ e do lote 3 com a menor porcentagem $(24,0 \%)$. Entretanto, esse ranqueamento não se aplica aos lotes com 24 horas de embebição, uma vez que a classificação apresentou o lote 4 como o de maior vigor (45,3\%), o lote 1 de vigor intermediário (39,7\%), o lote 2 , vindo em seguida $(35,0 \%)$ e o lote $3(27,8 \%)$ como aquele de mais baixo vigor.

Os principais componentes das sementes, responsáveis pela embebição e aumento de tamanho, são as proteínas e açúcares, e, em menor intensidade, a celulose e substâncias pécticas; o amido e os lipídios apresentam interferência reduzida no processo (BEWLEY et al., 2013). Sendo assim, as sementes possuindo níveis diferentes dessas substâncias, diferem na absorção. As sementes de moringa apresentam grande quantidade dessas substâncias e, dependendo do tamanho da semente, a embebição pode ocorrer de forma diferenciada (GALLÃO; DAMASCENO; BRITO, 2006).

Em pesquisas com sementes de soja, Marcos Filho, Kikuti e Lima (2009) observaram distinção entre lotes de sementes, quando a diferença de vigor era grande, com o uso de 4 ou 8 horas de embebição; entretanto, quando a diferença de qualidade entre os lotes era pequena, o período de embebição por 16 ou 20 horas mostrou-se mais sensível para detectar as variações do vigor das sementes daquela espécie. Além disso, os estágios iniciais de absorção de água pela semente de soja seca foram rastreados com imagens obtidas em momentos diferentes ao longo do tempo de embebição, em intervalos curtos, nos quais foram observados que o tamanho da semente aumentou em 30\%, no intervalo de 20 minutos, para cultivares que se apresentaram mais vigorosos. Em sementes de Dalbergia miscolobium, Oliveira et al. (2014) conseguiram detectar as diferenças de qualidade existentes entre os lotes mantidos sob as temperaturas de 40 e $50^{\circ} \mathrm{C}$ após 6 horas de embebição. Vanzolini e Nakagawa (1999), trabalhando com amendoim, observaram que o tempo de embebição de 3 horas foi suficiente para distinguir a qualidade de diferentes lotes de sementes. Nesta pesquisa, o período de 8 horas para a temperatura de $15^{\circ} \mathrm{C}$, utilizando-se sementes com o tegumento, apresentou melhor ranqueamento dos lotes, considerando o menor tempo de embebição para classificação, de acordo com os índices da caracterização fisiológica.

Quanto à temperatura de embebição, sua influência é verificada na velocidade de embebição e de lixiviação de eletrólitos, do interior das células para o meio externo. Loeffler (1981) constatou que a diminuição na temperatura causa aumento na viscosidade da solução, seguida por um decréscimo na mobilidade e consequente redução da perda de íons; em contrapartida, as altas temperaturas aumentam a dissociação de íns e reduz a viscosidade da solução, o que resulta em alto extravasamento de eletrólitos. As sementes que, mesmo diante de condições estressantes, conseguem atingir a germinação, nesse caso com baixa temperatura, são aquelas também consideradas mais vigorosas (MARCOS FILHO; KIKUTI; LIMA, 2009; BEWLEY et al., 2013), corroborando os dados obtidos no presente trabalho.

Comparou-se também a área das sementes com tegumento após 8 horas de hidratação, de forma individual com o comprimento de plântulas (Figura 2A), considerando-se as plântulas normais como aquelas que possuem pelo menos $6 \mathrm{~cm}$ de comprimento e aspecto saudável. 
Figura 2 - Distribuição da área $\left(\mathrm{mm}^{2}\right)$ das sementes com tegumento após 8 horas de embebição a $15^{\circ} \mathrm{C}(\mathrm{A})$ e distruibuição do comprimento $(\mathrm{cm})$ de plântulas (B), apresentando seus respectivos coeficientes de correlação de Pearson $(r)(C)$, em quatro lotes de Moringa oleifera.

Figure 2 - Distribution of the area $\left(\mathrm{mm}^{2}\right)$ of the seeds with integument after 8 hours of soaking at $15^{\circ} \mathrm{C}(\mathrm{A})$ and the distribution of length $(\mathrm{cm})$ of seedlings $(\mathrm{B})$, presenting their respective coefficients of Pearson correlation (r) ( C) in four lots of Moringa oleífera.

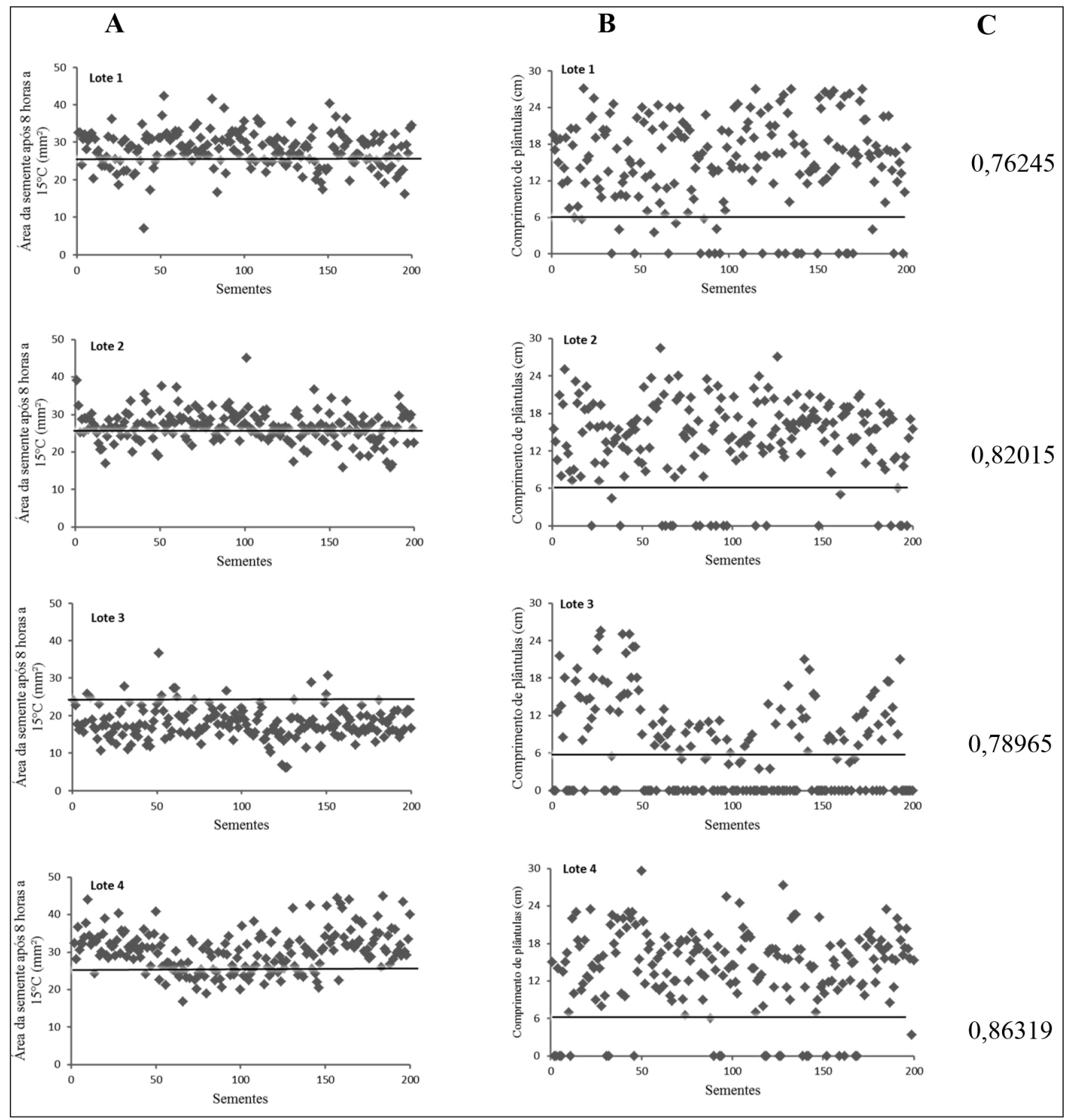

Observa-se que os lotes 1, 2 e 4 (Figura 2A) apresentam a maior parte das sementes com área superior a $25 \mathrm{~mm}^{2}$ (limite definido pela média da área dos quatro lotes), sendo o incremento de área (IA) maior para esses três lotes, enquanto, para o lote 3 (Figura 2A), observa-se maior parte das sementes abaixo desse valor, consequentemente apresentaram menor valor de incremento de área.

Verificou-se na distribuição do comprimento de plântulas para os quatro lotes de sementes testados (Figura 2B), que os lotes 1, 2 e 4 apresentaram maior quantidade de plântulas consideradas normais, enquanto no lote 3 esse valor é inferior, comparando-se com os demais lotes, pois este apresenta grande 
quantidade de sementes mortas e ainda plântulas que, apesar de possuírem mais de $6 \mathrm{~cm}$ de comprimento, apresentam alguma anomalia.

$\mathrm{Na}$ literatura ainda são escassos e praticamente inexistentes os trabalhos que relacionam o incremento de área da semente durante a embebição e os índices de germinação e vigor. Porém, é possível verificar, por meio dos resultados obtidos no presente trabalho, que esta premissa (aumento volumétrico $\mathrm{x}$ qualidade fisiológica) é verdadeira, uma vez que normalmente a semente aumenta drasticamente de tamanho na fase I e pouco na segunda fase (BEWLEY et al., 2013), sendo assim, o fenômeno de absorção da água afeta, portanto, as características morfodimensionais da semente e consequentemente o processo de germinação.

\section{Conclusão}

As sementes de moringa seguem o padrão trifásico de embebição, com a protrusão da radícula ocorrendo em 72 horas.

O período de 8 horas de embebição a $15^{\circ} \mathrm{C}$ demonstrou eficiência para categorização dos lotes quanto a sua qualidade, em comparação com os testes usualmente utilizados para a espécie.

O monitoramento do incremento de área das sementes durante a embebição por meio da análise de imagem mostrou-se uma ferramenta eficiente na avaliação da qualidade de sementes de moringa.

Os testes de vigor empregados foram eficientes da categorização em relação a qualidade dos lotes testados.

\section{Referências}

ALVARENGA, R. O.; MARCOS-FILHO, J.; GOMES JUNIOR, F. G. Avaliação do vigor de sementes de milho superdoce por meio da análise computadorizada de imagens de plântulas. Revista Brasileira de Sementes, Londrina, v. 34, p. 488-494, 2012.

ALVES, M. C. S. et al. Germinação de sementes e desenvolvimento de plântulas de Moringa oleifera Lam. em diferentes locais de germinação e submetidas à pré-embebição. Revista Ciência e Agrotecnologia, Lavras, v. 29, p. 1083-1087, 2005.

BECKERT, O. P.; MIGUEL, M. H.; MARCOS FILHO, J. Absorção de água e potencial fisiológico em sementes de soja de diferentes tamanhos. Scientia Agricola, Piracicaba, v. 57, p. 671-675, 2000.

BEWLEY, J. D. et al. Seeds: physiology of development, germination and dormancy. 3th ed. New York: Springer, 2013. $392 \mathrm{p}$.

BEZERRA, A. M. E.; MOMENTÉ, V. G.; MEDEIROS FILHO, S. Germinação de sementes e desenvolvimento de plântulas de moringa (Moringa oleifera Lam.) em função do peso da semente e do tipo de substrato. Horticultura Brasileira, Brasília, v. 22, n. 2, p. 295-299, 2004.

BRASIL. Ministério da Agricultura, Pecuária e Abastecimento. Regras para Análise de Sementes. Brasília: Mapa; ACS, 2009. 399 p.

CARVALHO, N. M.; NAKAGAWA, J. Sementes: ciência, tecnologia e produção. 4. ed. Jaboticabal: FUNEP,x' 2000. 424 p.

COLL, J. B. et al. Fisiologia vegetal. Madrid: Ediciones Pirámide, 2001. 566 p.

DELL'AQUILA, A. Digital imaging information technology applied to seed germination testing: a review. Sustainable Agriculture, Dordrecht, v. 29, p. 213-221, 2009.

FERREIRA, A. G.; BORGHETTI, F. Germinação do básico ao aplicado. Porto Alegre: Artmed. 2008. $323 \mathrm{p}$.

GALLÃO, M. I.; DAMASCENO, L. F.; BRITO, E. S. Avaliação química e estrutural da semente de mo- 
ringa. Revista Ciência Agronômica, Fortaleza, v. 37, n. 1, p. 106-109, 2006.

GUEDES, R. S. et al. Avaliação do potencial fisiológico de sementes de Amburana cearensis (Allemão) A.C. Smith. Bioscience Journal, Uberlândia, v. 29, n. 4, p. 859-866, 2013.

GOMES JUNIOR, F. G.; CHAMMA, H. M. C. P.; CICERO, S. M. Automated image analysis of seedlings for vigor evaluation of common bean seeds. Acta Scientiarum Agronomy, Maringá, v. 36, n. 2, p. 195-200, 2014.

GONELI, A. L. D. et al. Contração volumétrica e forma dos frutos de mamona durante a secagem. Acta Scientiarum Agronomy, Maringá, v. 33, n. 1, p. 1-8, 2011.

KOIZUMI, M. et al. Role of seed coat in imbibing soybean seeds observed by micro-magnetic resonance imaging. Annals of Botany, Oxford, v. 102.3, p. 343-352, 2008.

KRZYZANOWSKI, F. C.; VIEIRA, R. D.; FRANÇA NETO, J. B. Vigor de sementes: conceitos e testes. Londrina: ABRATES, 1999. $212 \mathrm{p}$.

LAZAROTTO, M. et al. Qualidade fisiológica e tratamentos de sementes de Cedrela fissilis procedentes do Sul do Brasil. Revista Árvore, Viçosa, MG, v. 37, n. 2, p. 201-210, 2013.

LOEFFLER, T. M. The bulk conductivity test as an indicator of soybean seed quality. 1981. $181 \mathrm{f}$. Thesis (Master of Science) - University of Kentucky, Lexington, 1981.

LORENZI, H.; MATOS, F. J. Plantas medicinais no Brasil: nativas e exóticas cultivadas. Nova Odessa: Instituto Plantarum, 2002. $512 \mathrm{p}$.

MAGUIRE, J. D. Speed of germination-aid in selection and evaluation for seedling emergence and vigor. Crop Science, Madison, v. 2, n. 2, p. 176-177, 1962.

MARCOS FILHO, J.; KIKUTI, A. L. P.; LIMA, L. B. Métodos para avaliação do vigor de sementes de soja, incluindo a análise computadorizada de imagens. Revista Brasileira de Sementes, Londrina, v. 31, p. 102-112, 2009.

NAKAGAWA, J. Testes de vigor baseados no desempenho das plântulas. In: KRZYZANOWSKI, F. C.; VIEIRA, R. D.; FRANÇA NETO, J. B. (Ed.). Vigor de sementes: conceitos e testes. Londrina: ABRATES, 1999. p. 2.1-2.24.

OLIVEIRA, D. V. et al. Teste de Envelhecimento acelerado para avaliação do vigor de sementes de Dalbergia miscolobium Benth. Heringeriana, Brasilia, v. 7, n. 2, p. 153-160, 2014.

RABBANI, A. R. C. et al. Pré-embebição em sementes de moringa. Scientia Plena, Sergipe, v. 9, n. 5, 2013.

RAMOS, L. M. et al. Morfologia de frutos e sementes e morfofunção de plântulas de Moringa (Moringa oleifera Lam.). Comunicata Scientiae, Teresina, v. 1, n. 2, p. 156, 2010.

RASHID, U.; ANWAR, F.; KNOTHE, G. Moringa oleifera oil: a possible source of biodiesel. Bioresource Technology, New York, v. 99, p. 8175-8179, 2008.

SILVA, P. P.; NASCIMENTO, W. M. Definição da metodologia para realização do teste de raios-X em sementes de abóbora. Horticultura Brasileira, Brasília, v. 28, n. 2, p. S4273-S4277, 2010.

SILVA, V. N. et al. Acca sellowiana O. Berg seed morphology evaluation by image analysis. Revista Brasileira de Fruticultura, Jaboticabal, v. 35, n. 4, p. 1158-1169, 2013.

SILVA, V. N.; CICERO, S. M.; BENNETT, M. Relação entre a morfologia interna e a germinação de sementes de berinjela. Revista Brasileira de Sementes, Londrina, v. 34, p. 597-604, 2012.

SOUZA, V. C.; LORENZI, H. Botânica Sistemática: guia ilustrado para identificação das famílias Fanerógamas nativas e exóticas no Brasil, baseado em APG II. 2. ed. Nova Odessa: Instituto Plantarum, 2008. $704 \mathrm{p}$. 
TAIZ, L.; ZEIGER, E. Fisiologia vegetal. 5. ed. Porto Alegre: Artmed, 2013. 820 p.

TARGINO, O. P. K. E. et al. Germinação e vigor de sementes de Moringa oleifera Lam. em diferentes sustratos e temperaturas. Revista Caatinga, Mossoró, v. 28, n. 2, 2015.

VANZOLINI, S.; NAKAGAWA, J. Teste de condutividade elétrica em sementes de amendoim, efeitos de teor de água inicial e de período de embebição. Revista Brasileira de Sementes, Londrina, v. 21, p. $46-52,1999$.

VARMA, V. S.; DURGA, K. K.; KESHAVULU, K. Seed image analysis: its applications in seed science research. International Research Journal of Agricultural Sciences, London, v. 2, p. 30-36, 2013.

WENDT, L. et al. Avaliação do potencial fisiológico de sementes de soja por meio de imagens. Pesquisa Agropecuária Tropical, Brasilia, v. 44, n. 3, 2014.

XU, L.; FUJIMURA, K.; MCDONALD, M. B. Automatic separation of overlapping seedlings by network optimization. Seed Science and Technology, Zurich, v. 35, p. 337-50, 2007.

ZABOT, L. et al. Use of digital images to evaluate field bean seedling growth. Revista Brasileira de Sementes, Londrina, v. 30, n. 2, p. 184-192, 2008. 